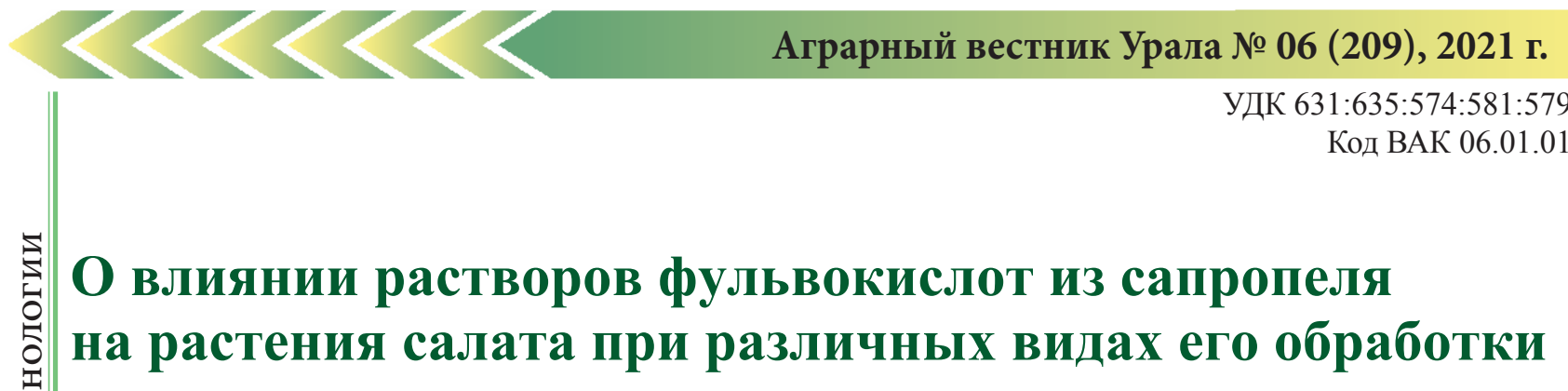

\author{
О. Р. Удалова ${ }^{1 \rrbracket}$, Г. В. Мирская ${ }^{1}$, П. Ю. Конончук ${ }^{1}$, Г. Г. Панова ${ }^{1}$ \\ ${ }^{1}$ Агрофизический научно-исследовательский институт, Санкт-Петербург, Россия \\ E-mail: udal59@inbox.ru
}

Аннотация. Целью исследования являлась оценка в регулируемых условиях интенсивной светокультуры влияния растворов фульвокислот, полученных из сапропеля, на физиологическое состояние, продукционный процесс и качество салатных культур при различных видах их обработки. Методология и методы исследования. Обработку растений растворами фульвокислот различной концентрации осуществляли в регулируемых условиях тремя способами: замачивание семян кресс-салата (0,03-300,0 мг/л); некорневая обработка вегетирующих растений (90,0-150,0 мг/л) при выращивании листового салата малообъемным методом с капельной подачей питательного раствора Кнопа; добавление в корнеобитаемую среду - питательный раствор $(0,03-$ 150,0 мг/л) при выращивании листового салата методом проточной гидропоники. Результаты. Установлено, что растворы фульвокислот оказывают наиболее выраженное стимулирующее влияние на показатели роста растений после обработки семян кресс-салата в концентрациях 0,3-150,0 мг/л, при некорневой обработке листового салата в концентрациях 0,3 и 150,0 мг/л и при введении в корнеобитаемую среду (питательный раствор) при концентрации 90,0 мг/л. Стимуляция роста растений салата под действием растворов фульвокислот преимущественно обусловлена: при некорневой обработке - усилением процессов обмена и поступления элементов питания в надземную часть растений; при введении в питательный раствор - усилением корневого питания и активизацией синтеза фотосинтетических пигментов хлорофиллов и каротиноидов. Научная новизна. В регулируемых условиях интенсивной светокультуры проведена комплексная оценка влияния растворов фульвокислот, полученных из сапропеля, на физиологическое состояние, продукционный процесс и качество салатных культур. Установлены концентрации растворов фульвокислот, оказавшие наиболее выраженное стимулирующее влияние на рост и развитие растений салата при различных видах их обработки. Выявлена специфика ответных реакций растений салата на различные виды их обработки растворами фульвокислот.

Ключевые слова: растворы фульвокислот, кресс-салат, салат, семена, замачивание, некорневая обработка, введение в корнеобитаемую среду, рост, продуктивность, эффективность фотосинтеза, биохимический состав, пигменты, сахара, витамин С, нитраты, макро- и микроэлементы.

Для цитирования: Удалова О. Р., Мирская Г. В., Конончук П. Ю., Панова Г. Г. О влиянии растворов фульвокислот из сапропеля на растения салата при различных видах его обработки // Аграрный вестник Урала. 2021. № 06 (209). C. 22-33. DOI: ...

Дата поступления статьи: 09.03.2021, дата рецензирования: 28.04.2021, дата принятия: 14.05.2021.

Постановка проблемы (Introduction)

Потребность АПК в разработке новых экологически безопасных, биоразлагаемых, стабильно эффективных, мультифункциональных и недорогих средств для оперативного управления продукционным процессом растений остается весьма актуальной. Одними из перспективных и широко используемых природных источников для создания указанных выше препаратов являются гуминовые вещества с высоким уровнем обогащения кислородными функциональными группами (карбоксильные, фенольные, гидроксильные, карбонильные и метоксильные) и высокой структурной гетерогенностью, являющиеся основной органической составляющей каустобиолитов угольного ряда, к которым относятся ископаемые угли, торфы, горючие сланцы и сапропели [1-3]. Как известно, среди гуминовых веществ фульвокислоты являются 22 наиболее активными, растворимыми в щелочных и кислых средах, имеющими более высокую общую кислотность, число карбоксильных групп, адсорбционные и катионообменные способности при меньших молекулярных размерах и атомной массе (всего несколько сотен Дальтон по сравнению с несколькими тысячами Дальтон у гуминовых кислот) [4-7]. Как показано в литературе, фульвокислоты могут выступать в роли природных хелаторов в мобилизации и транспорте железа и других микроэлементов [6], [7]. Благодаря малому молекулярному размеру фульвокислоты могут проходить через микропоры биологических или искусственных мембранных систем, в то время как гуминовые кислоты - нет. На примере растений кукурузы, сои и райграса показано, что обработка этих растений фульвокислотами повышала чистую продуктивность фотосинтеза, скорость 


\section{Agrarian Bulletin of the Urals No. 06 (209), 2021}

транспирации, а также межклеточные концентрации углекислого газа и хлорофилла [8-10]. Указанные механизмы влияния фульвокислот на физиологическое состояние растений частично объясняют выявленные как при некорневой обработке ими, так и при введении в почву эффекты увеличения биомассы корней и побегов, более раннее цветение укорененных черенков у ряда культур [7]. Установлено, что фульвокислоты значительно стимулируют прорастание семян на примере растений пшеницы [11], увеличивают площадь листьев и надземную сухую массу проростков при обработке семян в исследованиях, проведенных в теплице и климатической камере [7], [12], [13]. В литературе также отмечается положительная роль фульвокислоты в повышении устойчивости растений к засухе, тяжелым металлам, в улучшении усвоения питательных веществ, к окислительному стрессу, стабилизации $\mathrm{pH}$ почвы и снижении выщелачивания удобрений [10], [14-17]. Однако механизмы влияния фульвокислоты на устойчивость растений к абиотическим стрессам остаются малоизученными [12].

И в целом, несмотря на большой интерес у исследователей к изучению влияния гумусовых и фульво- кислот на растения, в литературе отмечается недостаточность данных для представления всех путей трансформации их в растении и влияния на физиологические процессы [7], [12]. Особенно мало работ, посвященных влиянию фульвокислот, полученных из сапропелей, являющихся, как известно, донными отложениями пресноводных водоемов, представляющих собой многокомпонентные полидисперсные системы, которые из остатков планктонных и бентосных организмов, при большой роли бактериальных процессов, происходящих в поверхностных слоях отложений при малом доступе кислорода [18]. Для понимания особенностей влияния именно фульвокислот на растения, выявления диапазона их оптимальных концентраций необходимо проведение исследований в регулируемых условиях на примере фитотест-культуры.

Целью настоящего исследования являлась оценка в регулируемых условиях интенсивной светокультуры влияния растворов фульвокислот, полученных из сапропеля, на физиологическое состояние, продукционный процесс и качество салатных культур при различных видах их обработки.

Таблица 1

Химический состав исходных фульвокислот

\begin{tabular}{|c|c|c|}
\hline Анализируемый показатель & Единица измерения & Результаты испытаний \\
\hline Влажность & $\%$ & 88,4 \\
\hline Органическое вещество & $\%$ с. в. & 26,2 \\
\hline Содержание золы & $\%$ с. в. & 73,8 \\
\hline Углерод фульвокислот & $\%$ н. в. & 3,05 \\
\hline Содержание азота & $\%$ Н. в. & 0,016 \\
\hline Содержание фосфора в пересчете на $\mathrm{P}_{2} \mathrm{O}_{5}$ & $\%$ н. в. & 1,97 \\
\hline Содержание калия в пересчете на $\mathrm{K}_{2} \mathrm{O}$ & $\%$ н. в. & 4,47 \\
\hline Содержание меди & МГ/КГ Н. В. & 0,075 \\
\hline Содержание цинка & МГ/КГ н. в. & 1,061 \\
\hline Содержание марганца & МГ/КГ Н. В. & 1,650 \\
\hline Содержание железа & МГ/Кг Н. в. & 7,800 \\
\hline Содержание кобальта & МГ/КГ Н. В. & 0,074 \\
\hline Содержание магния & МГ/КГ Н. В. & 55,18 \\
\hline
\end{tabular}

Примечание. С. в. - сухое вещество, н. в. - натуральная влага.

Table 1

Chemical composition of the initial fulvic acids

\begin{tabular}{|c|c|c|}
\hline Indicators & Unit of measurement & Test results \\
\hline Moisture content & $\%$ & 88.4 \\
\hline Organic matter & $\% d . m$. & 26.2 \\
\hline Ash content & $\% d . m$. & 73.8 \\
\hline Carbon of fulvic acids & $\% n . m$. & 3.05 \\
\hline Nitrogen & $\% n . m$. & 0.016 \\
\hline Phosphorus in terms of $\mathrm{P}_{2} \mathrm{O}_{5}$ & $\% n . m$. & 1.97 \\
\hline Potassium in terms of $\mathrm{K}_{2} \mathrm{O}$ & $\% n . m$. & 4.47 \\
\hline Copper & $m g / k g ~ n . m$. & 0.075 \\
\hline Zinc & $m g / k g ~ n . m$. & 1.061 \\
\hline Manganese & $m g / k g ~ n . m$. & 1.650 \\
\hline Iron & $m g / k g ~ n . m$. & 7.800 \\
\hline Cobalt & $m g / k g ~ n . m$. & 0.074 \\
\hline Magnesium & $m g / k g ~ n . m$. & 55.2 \\
\hline
\end{tabular}


Таблица 2

Влияние растворов фульвокислот различной концентрации на энергию прорастания, всхожесть семян и ростовые характеристики семидневных проростков кресс-салата сорта Ажур

\begin{tabular}{|c|c|c|c|c|c|c|c|c|}
\hline \multirow{2}{*}{$\begin{array}{c}\text { Концентрация } \\
\text { растворов } \\
\text { фульвокислот } \\
\text { мг/л }\end{array}$} & \multicolumn{2}{|c|}{$\begin{array}{c}\text { Энергия } \\
\text { прорастания }\end{array}$} & \multicolumn{2}{|c|}{ Всхожесть } & \multicolumn{2}{|c|}{ Длина ростка } & \multicolumn{2}{|c|}{ Длина корня } \\
\hline & $\%$ & $\begin{array}{c}\text { \% от } \\
\text { контроля }\end{array}$ & $\%$ & $\begin{array}{c}\% \text { от } \\
\text { контроля } \\
\end{array}$ & см & $\begin{array}{c}\text { \% от } \\
\text { контроля }\end{array}$ & $\mathbf{c M}$ & $\begin{array}{c}\text { \% от } \\
\text { контроля }\end{array}$ \\
\hline 0 (контроль) & 96 & 100 & 98 & 100 & $4,6 \pm 0,2$ & 100 & $8,6 \pm 0,9$ & 100 \\
\hline 300 & 89 & 93 & Погибли & Погибли & Погибли & Погибли & Погибли & Погибли \\
\hline 150 & 100 & 104 & 98 & 100 & $5,3 \pm 0,2 *$ & $115^{*}$ & $5,4 \pm 0,4^{*}$ & $63 *$ \\
\hline 30 & 96 & 100 & 100 & 102 & $5,3 \pm 0,2 *$ & $115^{*}$ & $10,6 \pm 0,8 *$ & $123 *$ \\
\hline 3 & 90 & 94 & 100 & 102 & $5,2 \pm 0,2^{*}$ & $113^{*}$ & $8,9 \pm 0,8$ & 103 \\
\hline 0,3 & 94 & 98 & 100 & 102 & $5,1 \pm 0,2^{*}$ & $111 *$ & $9,6 \pm 0,7$ & 112 \\
\hline 0,03 & 96 & 100 & 98 & 100 & $4,8 \pm 0,3$ & 104 & $8,7 \pm 0,7$ & 101 \\
\hline
\end{tabular}

Примечание. * Значение достоверно отличается от контроля на 5-прочентном уровне значимости.

Table 2

The effect of FA solutions of various concentrations on germination energy, germination of seeds and growth characteristics of seven-day watercress seedlings of variety Azur

\begin{tabular}{|c|c|c|c|c|c|c|c|c|}
\hline \multirow{2}{*}{$\begin{array}{c}\text { The concentration } \\
\text { of the } F A \\
\text { solutions, } \mathrm{mg} / \mathrm{l}\end{array}$} & \multicolumn{2}{|c|}{$\begin{array}{c}\text { Germination } \\
\text { energy }\end{array}$} & \multicolumn{2}{|c|}{ Germination } & \multicolumn{2}{|c|}{ Shoot length } & \multicolumn{2}{|c|}{ Root length } \\
\hline & $\%$ & $\begin{array}{c}\% \text { of } \\
\text { control }\end{array}$ & $\%$ & $\begin{array}{c}\% \text { of } \\
\text { control }\end{array}$ & $\mathrm{cm}$ & $\begin{array}{c}\text { \% of } \\
\text { control }\end{array}$ & $\mathrm{cm}$ & $\begin{array}{c}\% \text { of } \\
\text { control }\end{array}$ \\
\hline 0 (control) & 96 & 100 & 98 & 100 & $4.6 \pm 0.2$ & 100 & $8.6 \pm 0.9$ & 100 \\
\hline 300 & 89 & 93 & Died & Died & Died & Died & Died & Died \\
\hline 150 & 100 & 104 & 98 & 100 & $5.3 \pm 0.2 *$ & $115^{*}$ & $5.4 \pm 0.4^{*}$ & $63 *$ \\
\hline 30 & 96 & 100 & 100 & 102 & $5.3 \pm 0.2 *$ & $115^{*}$ & $10.6 \pm 0.8 *$ & $123 *$ \\
\hline 3 & 90 & 94 & 100 & 102 & $5.2 \pm 0.2 *$ & $113 *$ & $8.9 \pm 0.8$ & 103 \\
\hline 0.3 & 94 & 98 & 100 & 102 & $5.1 \pm 0.2 *$ & $111^{*}$ & $9.6 \pm 0.7$ & 112 \\
\hline 0.03 & 96 & 100 & 98 & 100 & $4.8 \pm 0.3$ & 104 & $8.7 \pm 0.7$ & 101 \\
\hline
\end{tabular}

Note. ${ }^{*}$ The value is significantly different from the control at a $5 \%$ significance level.

\section{Методология и методы исследования (Methods)}

Предметом исследования служили водорастворимые фульвокислоты, полученные из сапропелей озер Псковской области стандартным методом химического осаждения фракции гуминовых кислот с последующей фильтрацией [19].

Оценку влияния растворов фульвокислот на растения проводили на базе ФГБНУ АФИ в лабораторных условиях и на биополигоне в регулируемых условиях интенсивной светокультуры [20].

Объектами исследования являлись кресс-салат (Lepidium sativum L.) сорта Ажур, листовой салат (Lactuca sativa L.) сорта Тайфун селекции АО ССПП «Сортсемовощ».

Обработку растений растворами фульвокислот различной концентрации осуществляли тремя способами: замачивание семян (0,03-300,0 мг/л), некорневая обработка вегетирующих растений (0,3-150,0 мг/л), подача в составе корнеобитаемой среды - питательного раствора (0,03-150,0 мг/л).

Изучение биологической активности растворов фульвокислот включало определение их влияния в широком диапазоне концентраций на энергию прорастания и всхожесть семян кресс-салата, а также на биометрические показатели роста его 7-дневных проростков (длина ростков и корней). Исследования выполнены в трехкратной повторности в соответствии с общепринятыми методами и правилами международной ассоциации тестирования семян [21].
Для оценки влияния растворов фульвокислот на вегетирующие растения салата сорта Тайфун выращивание проводили в вегетационных светоустановках $(\mathrm{BCУ})^{1}$, оснащенных световыми блоками с натриевыми лампами ДНа3-400 (ООО Рефлакс Россия). Облученность растений составляла 80-90 Вт/м² ФАР, продолжительность светового периода - 14 часов. Температура воздуха поддерживалась в пределах $+22 \ldots 24{ }^{\circ} \mathrm{C}$ днем и $+18 \ldots 20{ }^{\circ} \mathrm{C}$ ночью, относительная влажность воздуха - 65-70 \%.

В качестве корнеобитаемой среды использовали органоминеральный аналог почвы Агрофит². Для полива в течении вегетации в обоих экспериментах применяли питательный раствор Кнопа [22]. На 1 м² ВСУ формировали ценоз из расчета 50 растений салата. Для оценки влияния некорневой обработки на рост и развитие растений тестируемых растворов рассаду салата высаживали в емкости объемом 0,7 л (1 растение на емкость). Повторность - 20 растений в варианте опыта. Подачу питательного раствора к корням растений осуществляли методом капельного полива. Некорневую обработку в концентрациях 0,3-150,0 мг/л проводили 3 раза с периодичностью 5 суток на протяжении фаз развития 4-8 листьев. В контрольном варианте применяли обработку водой.

${ }^{1}$ Желтов Ю. И., Панова Г. Г. Устройство для выращивания растений. Патент на полезную модель № 108705. 2011. Бюл. № 27.

${ }^{2}$ Ермаков Е. И., Желтов Ю. И., Мильто Н. Е., Кучеров В. И. Почвогрунт для выращивания растений «Агрофит». Патент № 2081555 РФ. 1997. БИ № 17. 
Исследование влияния тестируемых растворов фульвокислот посредством их введения в корнеобитаемую среду (питательный раствор) на рост и развитие растений салата проводили при выращивании его методом проточной тонкослойной гидропоники (NFT)3. Рассаду салата высаживали в пластиковые горшочки (PR-306) диаметром и высотой 5 см с отверстиями на дне и боковых стенках и размещали в ВСУ, оснащенную системой проточного культивирования (5 растений на культивационный желоб), повторность - 20 растений в варианте. В питательный раствор Кнопа вводили растворы фульвокислот в концентрациях 0,03-150,0 мг/л. В контрольном варианте использовали раствор Кнопа без фульвокислот. Вегетационный эксперимент проводили дважды. Уборку осуществляли на 28-е сутки от посева семян. При уборке учитывали высоту растений, число листьев, сырую и сухую массу надземной части, процентное содержание сухого вещества, удельную поверхностную плотность листа (УППЛ), обводненность листьев [23], а также площадь листовой поверхности, индекс листовой поверхности (ИПЛ), чистую продуктивность фотосинтеза (ЧПФ), фотосинтетический потенциал (ФП) [9].

Химический состав исходных фульвокислот и биохимический состав растений определяли виспытательной лаборатории ФГБНУ АФИ в соответствии с требованиями нормативных документов (таблица 1) [24].

На основании полученных данных был выбран диапазон концентраций водных растворов фульвокислот $(0,3-150,0$ мг/л) - для некорневой обработки растений листового салата и $(0,03-150,0$ мг/л) для введения в корнеобитаемую среду (питательный раствор) при выращивании салата методом проточной тонкослойной гидропоники.

Некорневая обработка растений салата сорта Тайфун растворами фульвокислот в указанных концентрациях способствовала достоверному повышению массы надземной части растений, что было связано, очевидно, с выявленным увеличением числа листьев, их площади и удельной поверхностной плотности (таблица 3,4$)$.

Статистическую обработку данных осуществляли с использованием программ Excel 2010 и Statistica 8 (Stat-Soft, Inc., США). Определяли средние значения изучаемых показателей, доверительные интервалы и коэффициенты вариации. Достоверность различий между вариантами оценивали при помощи методов параметрической статистики ( $t$-критерий Стьюдента). Различия между вариантами считались достоверными при $p \leq 0,05$.

\section{Результаты (Results)}

Оценка результатов обработки семян кресс-салата сорта Ажур водными растворами фульвокислот в диапазоне 0,03-300,0 мг/л (таблица 2) выявила:

- отсутствие достоверного влияния на энергию прорастания при концентрациях 0,03-300,0 мг/л и всхожесть - при концентрациях 0,03-150,0 мг/л;

${ }^{3}$ Шишкин П. В. Антипова О. В. Способ гидропонного бессубстратного выращивания растений и устройство для его осуществления (варианты). Патент РФ 2635396. Бюл. № 32.13.11.2017. НФТ. гибель проростков кресс-салата на стадии всхожести при концентрации 300,0 мг/л и выше;

достоверное положительное влияние на рост ростков и корней при концентрации 30,0 мг/л, только ростков при концентрации 0,3-150,0 мг/л, в виде тенденции ростков при концентрации 0,03 мг/л, а корней - при концентрации 0,03-3,0 мг/л;

- достоверное торможение роста корней в варианте с обработкой семян кресс-салата раствором фульвокислот с концентрацией 150,0 мг/л.

Наиболее отчетливо указанные изменения проявлялись в вариантах с обработкой растений растворами фульвокислот в концентрациях 3,0 и 150,0 мг/л. Возможными причинами отмеченного положительного влияния на показатели роста растений, по всей видимости, являются:

увеличение поступления в надземную часть обработанных растений минеральных элементов питания, в том числе кальция, магния и железа, на что указывает достоверное или в виде тенденции повышение их содержания в листьях (таблица 5);

- $\quad$ накопление органических соединений в виде достоверного увеличения суммы сахаров во всех исследуемых вариантах (рис. 1).

Указанные процессы при малых концентрациях фульвокислот (3,0 мг/л) преимущественно обусловлены их способностью действовать в качестве специфических сенсибилизирующих агентов, увеличивающих проницаемость плазматических мембран, что приводит к мобилизации и усилению транспорта питательных веществ к хозяйственно ценным органам растений. В более высоких концентрациях (150,0 мг/л) фульвокислоты выступают дополнительным источником макро- и микроэлементов, а также органических соединений, обладающих высокой биологической активностью [5], [11], [25].

На фоне общего положительного влияния некорневой обработки растений салата растворами фульвокислот снижение обводненности листьев не оказало отрицательного воздействия на ростовые и обменные процессы растений. При этом, несмотря на достоверное или в виде небольшой тенденции снижение фотосинтетических пигментов (хлорофилла А и $\mathrm{B}$, каротиноидов) в вариантах обработки растворами фульвокислот в диапазоне концентраций 3,0-30,0 и 90,0-150,0 мг/л отмечалась стимуляция фотосинтетических процессов: увеличение ИЛП и ФП на 4-19 \% и ЧПФ на 20-32 \% (таблица 4).

Вероятно, усиление эффективности фотосинтеза сопряжено с накоплением микроэлемента железа, которое катализирует образование предшественников пигмента хлорофилла А - аминолевулиновой кислоты и протопорфиринов. Кроме того, соединения железа задействованы в образовании компонентов хлоропластов: цитохромы, ферредоксин и др. По всей видимости, с увеличением содержания железа в листьях при некорневой обработке растений салата снижается необходимость синтеза вторичных метаболитов, в том числе фотосинтетических пигментов. 


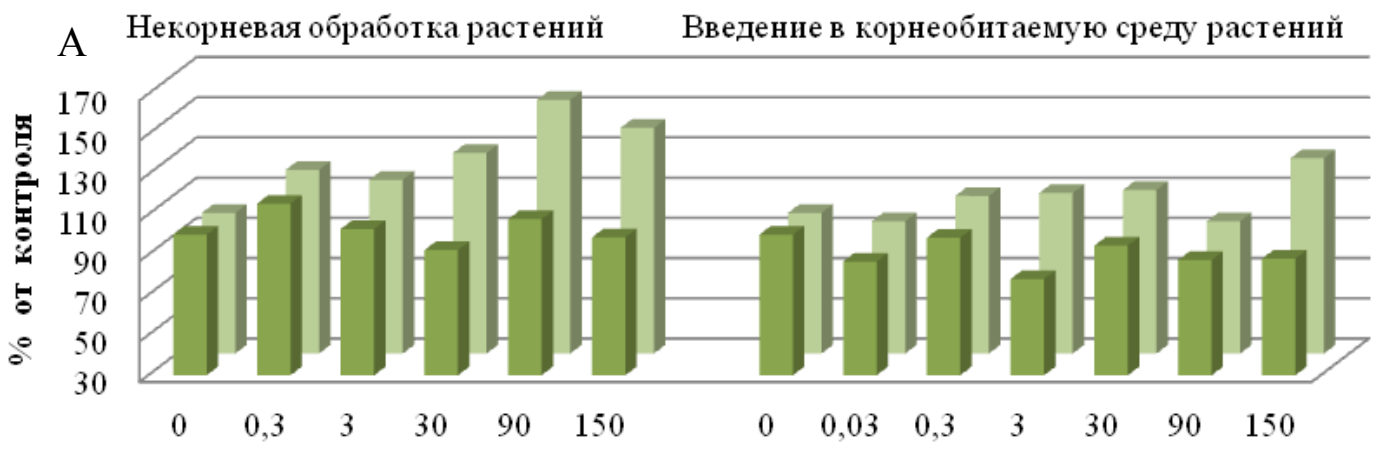

витамин С- Суммасахаров Концентрациирастворов, мг/л

Б Некорневая обработка растений Введение в корнеобитаемую среду растений

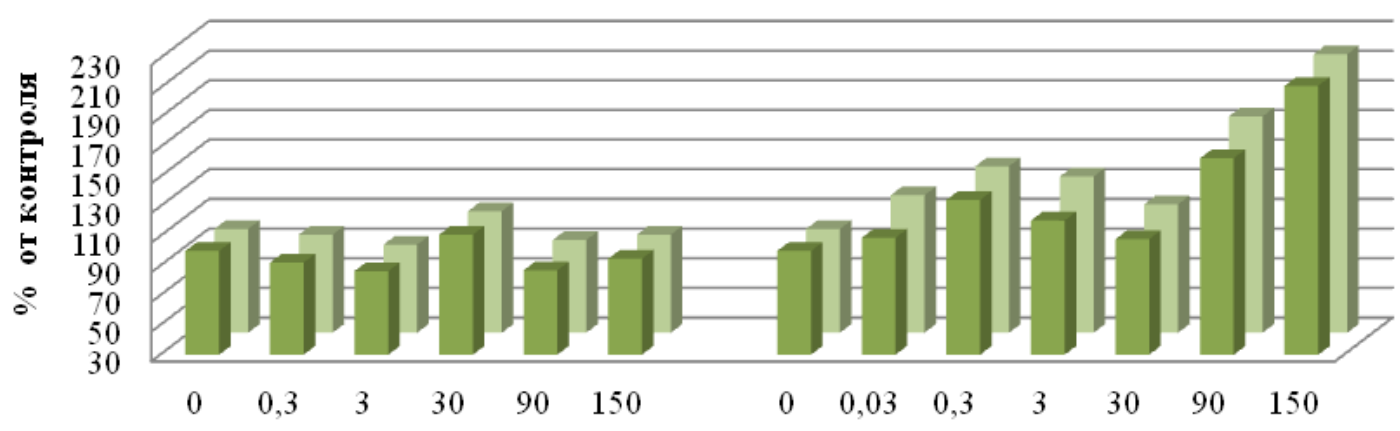

пуммахлор офиллов а и b

Рис. 1. Влияние некорневой обработки и введения в корнеобитаемую среду растворов фульвокислот на биохимические показатели растений салата: сумма сахаров, витамин С (А), пигменты (Б) в регулируемых условиях интенсивной светокультуры
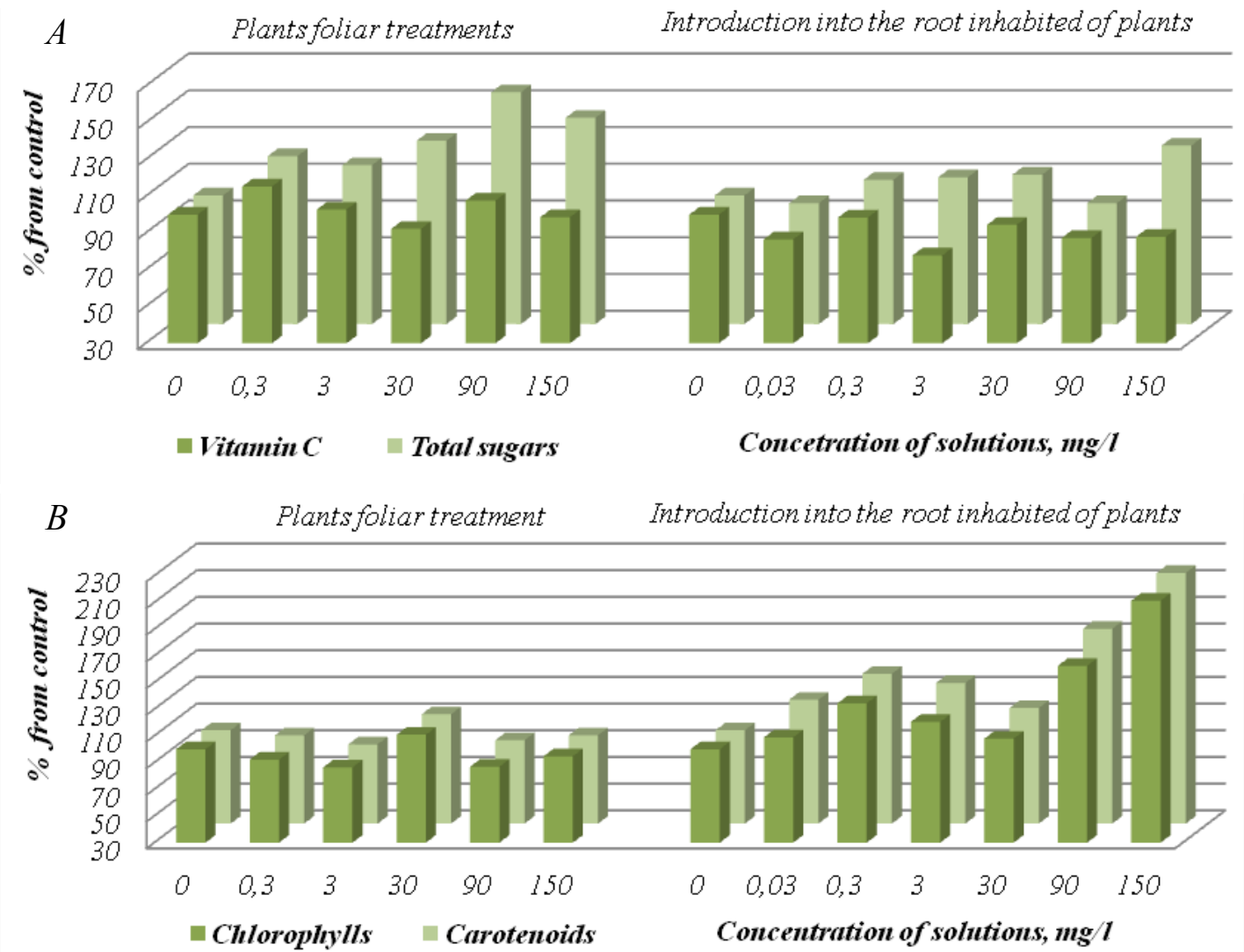

Fig. 1. The effect the foliar treatment with FA solutions and introduction into the root inhabited medium on the biochemical parameters of lettuce plants: sugars, Vitamin C (A). pigments (B) under intensive controlled conditions 


\section{Agrarian Bulletin of the Urals No. 06 (209), 2021}

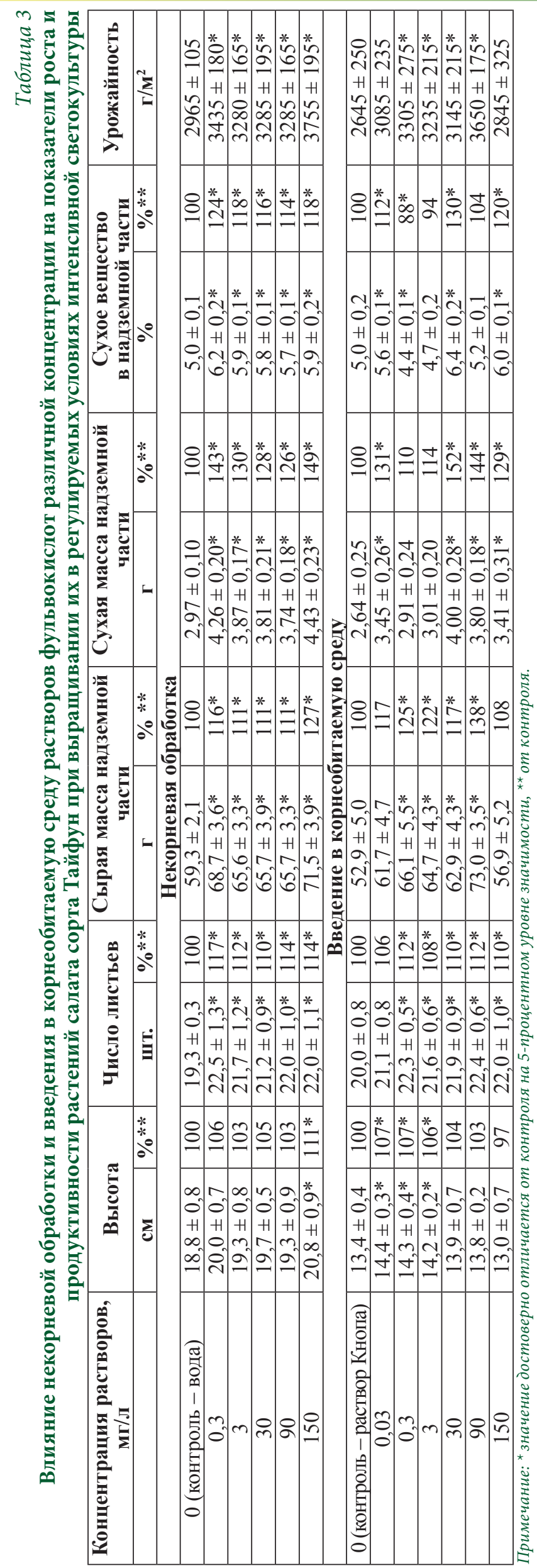

m 
Таблиц, 4

Показатели фотосинтетической активности листьев салата сорта Тайфун при некорневой обработке и введении в корнеобитаемую среду растворов фульвокислот

\begin{tabular}{c|c|c|}
$\begin{array}{c}\text { Концентра- } \\
\text { ция } \\
\text { растворов, } \\
\text { мг/л }\end{array}$ & $\begin{array}{c}\text { Площадь } \\
\text { листьев, } \\
\text { дм²/растение }\end{array}$ & $\begin{array}{c}\text { Удельная } \\
\text { порхностная } \\
\text { плотность } \\
\text { листа, г/дм }\end{array}$ \\
\hline
\end{tabular}
различной концентрации при выращивании растений в регулируемых условиях интенсивной светокультуры

\begin{tabular}{l|l|l|l} 
Индекс & Фотосинте- & Чистая про- & Обводнен- \\
\hline
\end{tabular}

Индекс
листовой
поверхно-
сти, дм²/дм

Фотосинте-
тический
потенцил,
Чистая профотосинтеза, г/М $\mathbf{M}^{2}$ сутки ность Некорневая обработка

\begin{tabular}{|c|c|c|c|c|c|c|}
\hline $\begin{array}{c}0 \text { (контроль } \\
\text { вода) }\end{array}$ & $29,09 \pm 1,03$ & $0,102 \pm 0,0002$ & $14,5 \pm 0,52$ & $4,07 \pm 0,14$ & $0,73 \pm 0,01$ & $20,0 \pm 0,04$ \\
\hline 0,3 & $31,72 \pm 1,66$ & $0,134 \pm 0,0007^{*}$ & $15,9 \pm 0,83^{*}$ & $4,44 \pm 0,23$ & $0,96 \pm 0,01^{*}$ & $15,1 \pm 0,08^{*}$ \\
\hline 3 & $30,29 \pm 1,52$ & $0,128 \pm 0,0008^{*}$ & $15,1 \pm 0,76$ & $4,24 \pm 0,21$ & $0,91 \pm 0,01^{*}$ & $16,0 \pm 0,05^{*}$ \\
\hline 30 & $30,34 \pm 1,80$ & $0,126 \pm 0,0006^{*}$ & $15,2 \pm 0,90$ & $4,25 \pm 0,25$ & $0,89 \pm 0,01^{*}$ & $16,2 \pm 0,07^{*}$ \\
\hline 90 & $30,34 \pm 1,52$ & $0,123 \pm 0,0003^{*}$ & $15,2 \pm 0,76$ & $4,25 \pm 0,21$ & $0,88 \pm 0,01^{*}$ & $16,6 \pm 0,03^{*}$ \\
\hline 150 & $34,68 \pm 1,80^{*}$ & $0,128 \pm 0,0001^{*}$ & $17,3 \pm 0,90^{*}$ & $4,86 \pm 0,25^{*}$ & $0,91 \pm 0,01^{*}$ & $15,1 \pm 0,05^{*}$ \\
\hline \multicolumn{7}{|c|}{ Введение в корнеобитаемую среду } \\
\hline
\end{tabular}

\begin{tabular}{|c|c|c|c|c|c|c|}
\hline $\begin{array}{c}0 \text { (контроль }- \\
\text { раствор } \\
\text { Кнопа) }\end{array}$ & $20,76 \pm 1,96$ & $0,127 \pm 0,0001$ & $10,4 \pm 0,98$ & $2,91 \pm 0,27$ & $0,91 \pm 0,01$ & $19,0 \pm 0,01$ \\
\hline 0,03 & $25,49 \pm 1,94^{*}$ & $0,135 \pm 0,0002^{*}$ & $12,7 \pm 0,97^{*}$ & $3,57 \pm 0,27^{*}$ & $0,97 \pm 0,01^{*}$ & $16,9 \pm 0,02^{*}$ \\
\hline 0,3 & $25,94 \pm 2,16^{*}$ & $0,112 \pm 0,0002^{*}$ & $13,0 \pm 1,08^{*}$ & $3,63 \pm 0,30^{*}$ & $0,85 \pm 0,01^{*}$ & $21,7 \pm 0,03^{*}$ \\
\hline 3 & $25,39 \pm 1,69^{*}$ & $0,118 \pm 0,0001^{*}$ & $12,7 \pm 0,85^{*}$ & $3,55 \pm 0,24^{*}$ & $0,85 \pm 0,01^{*}$ & $20,6 \pm 0,04^{*}$ \\
\hline 30 & $25,99 \pm 1,78^{*}$ & $0,154 \pm 0,0002^{*}$ & $13,0 \pm 0,89^{*}$ & $3,64 \pm 0,25^{*}$ & $1,10 \pm 0,01^{*}$ & $14,7 \pm 0,02^{*}$ \\
\hline 90 & $30,16 \pm 1,45^{*}$ & $0,12 \pm 0,0001^{*}$ & $15,1 \pm 0,73^{*}$ & $4,22 \pm 0,20^{*}$ & $0,90 \pm 0,01$ & $18,2 \pm 0,01^{*}$ \\
\hline 150 & $23,51 \pm 2,15$ & $0,145 \pm 0,0001^{*}$ & $11,8 \pm 1,08$ & $3,29 \pm 0,30$ & $1,04 \pm 0,01^{*}$ & $15,7 \pm 0,01^{*}$ \\
\hline
\end{tabular}

Примечание. ${ }^{*}$ Значение достоверно отличается от контроля на 5-процентном уровне значимости.

Table 4

Indicators of photosynthetic activity of variety Typhoon lettuce leaves by foliar treatment with FA solutions and introduction into the root inhabited medium when plants growing under intensive controlled conditions

\begin{tabular}{|c|c|c|c|c|c|c|}
\hline $\begin{array}{c}\text { The concen- } \\
\text { tration } \\
\text { of the } \mathrm{mg} / \mathrm{l}\end{array}$ & $\begin{array}{c}\text { Leaf surface } \\
\text { area, } \\
\mathrm{dm}^{2} / p l a n t\end{array}$ & $\begin{array}{c}\text { The specific } \\
\text { surface density } \\
\text { of the leaf, } \\
\mathrm{g} / \mathrm{dm}^{2}\end{array}$ & $\begin{array}{l}\text { Index of } \\
\text { a leaf surface, } \\
\mathrm{dm}^{2} / \mathrm{dm}^{2}\end{array}$ & $\begin{array}{l}\text { Photosynthet- } \\
\text { ic potential, } \\
\mathrm{dm}^{2} / \mathrm{m}^{2} \text { days }\end{array}$ & $\begin{array}{c}\text { Net photosyn- } \\
\text { thesis } \\
\text { productivity } \\
\text { g/m } \text { m }^{2} \text { day }\end{array}$ & $\begin{array}{l}\text { Watering of } \\
\text { leaves, } \mathrm{g} / \mathrm{g}\end{array}$ \\
\hline \multicolumn{7}{|c|}{ Foliar treatment } \\
\hline $\begin{array}{c}0 \text { (control- } \\
\text { water) }\end{array}$ & $29.09 \pm 1.03$ & $0.102 \pm 0.0002$ & $14.5 \pm 0.52$ & $4.07 \pm 0.14$ & $0.73 \pm 0.01$ & $20.0 \pm 0.04$ \\
\hline 0,3 & $31.72 \pm 1.66$ & $0.134 \pm 0.0007^{*}$ & $15.9 \pm 0.83^{*}$ & $4.44 \pm 0.23$ & $0.96 \pm 0.01 *$ & $15.1 \pm 0.08 *$ \\
\hline 3 & $30.29 \pm 1.52$ & $0.128 \pm 0.0008 *$ & 15. \pm 0.76 & $4.24 \pm 0.21$ & $0.91 \pm 0.01 *$ & $16.0 \pm 0.05 *$ \\
\hline 30 & $30.34 \pm 1.80$ & $0.126 \pm 0.0006^{*}$ & $15.2 \pm 0.90$ & $4.25 \pm 0.25$ & $0.89 \pm 0.01 *$ & $16.2 \pm 0.07 *$ \\
\hline 90 & $30.34 \pm 1.52$ & $0.123 \pm 0.0003 *$ & $15.2 \pm 0.76$ & $4.25 \pm 0.21$ & $0.88 \pm 0.01 *$ & $16.6 \pm 0.03 *$ \\
\hline 150 & $34.68 \pm 1.80 *$ & $0.128 \pm 0.0001 *$ & $17.3 \pm 0.90^{*}$ & $4.86 \pm 0.25 *$ & $0.91 \pm 0.01 *$ & $15.1 \pm 0.05 *$ \\
\hline \multicolumn{7}{|c|}{ Introduction into the root inhabited medium } \\
\hline $\begin{array}{c}0 \text { (control- } \\
\text { Knop } \\
\text { solution) }\end{array}$ & $20.76 \pm 1.96$ & $0.127 \pm 0.0001$ & $10.4 \pm 0.98$ & $2.91 \pm 0.27$ & $0.91 \pm 0.01$ & $19.0 \pm 0.01$ \\
\hline 0,03 & $25.49 \pm 1.94^{*}$ & $\begin{array}{c}0.135 \pm 0.0002 \\
*\end{array}$ & $12.7 \pm 0.97 *$ & $3.57 \pm 0.27 *$ & $0.97 \pm 0.01 *$ & $16.9 \pm 0.02 *$ \\
\hline 0,3 & $25.94 \pm 2.16^{*}$ & $0.112 \pm 0.0002 *$ & $13.0 \pm 1.08^{*}$ & $3.63 \pm 0.30^{*}$ & $0.85 \pm 0.01 *$ & $21.7 \pm 0.03^{*}$ \\
\hline 3 & $25.39 \pm 1.69 *$ & $0.118 \pm 0.0001 *$ & $12.7 \pm 0.85 *$ & $3.55 \pm 0.24^{*}$ & $0.85 \pm 0.01 *$ & $20.6 \pm 0.04 *$ \\
\hline 30 & $25.99 \pm 1.78^{*}$ & $0.154 \pm 0.0002 *$ & $13.0 \pm 0.89 *$ & $3.64 \pm 0.25 *$ & $1.10 \pm 0.01 *$ & $14.7 \pm 0.02 *$ \\
\hline 90 & $30.16 \pm 1.45 *$ & $0.126 \pm 0.0001 *$ & $15.1 \pm 0.73^{*}$ & $4.22 \pm 0.20^{*}$ & $0.90 \pm 0.01$ & $18.2 \pm 0.01 *$ \\
\hline 150 & $23.51 \pm 2.15$ & $0.145 \pm 0.0001 *$ & $11.8 \pm 1.08$ & $3.29 \pm 0.30$ & $1.04 \pm 0.01 *$ & $15.7 \pm 0.01 *$ \\
\hline
\end{tabular}




\section{Agrarian Bulletin of the Urals No. 06 (209), 2021}

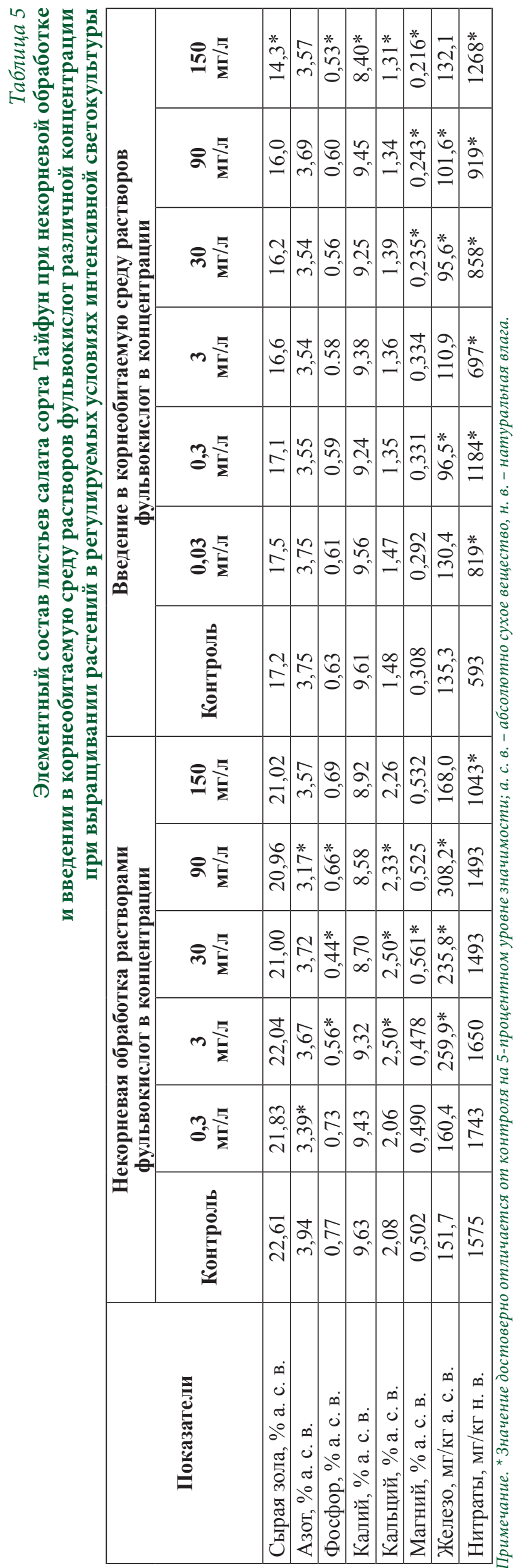

$\frac{\sqrt{0}}{0}$

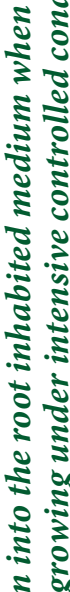

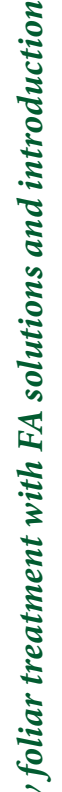

空

$\stackrel{5}{3}$

.

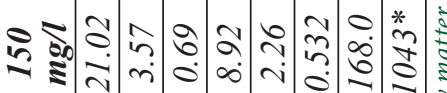

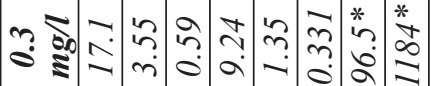

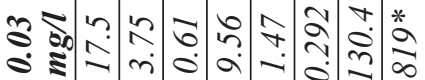

5

(

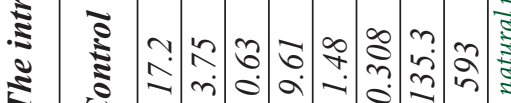

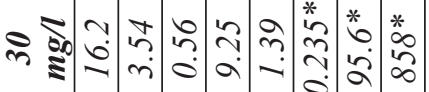

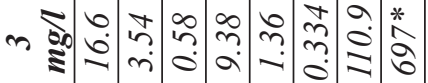

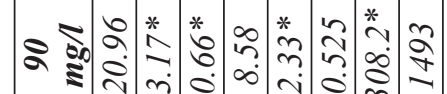

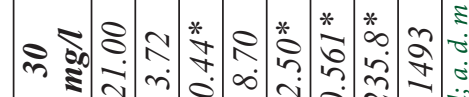

ฐ

בั

.

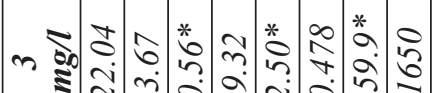

ฐ

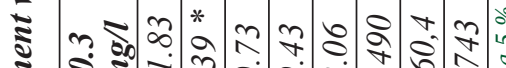

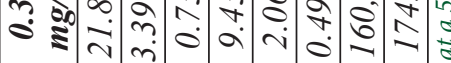

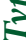

z

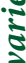

5

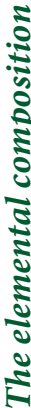

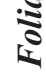

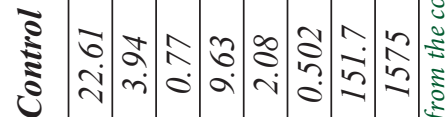

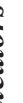

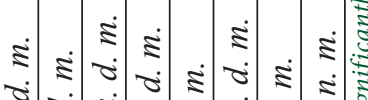

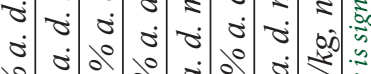

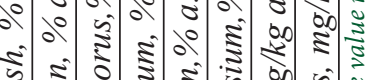

ปิ

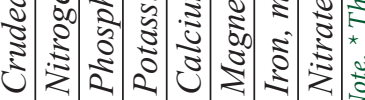


Вместе с тем достоверное увеличение углеводов, задействованных в процессах фотосинтеза и окислительно-восстановительных процессах, свидетельствовало о достаточно высоком уровне ассимиляционной работы листьев: увеличение площади листьев на 4-19 \%; УППЛ на 20-31 \%; сухого вещества - на 14-24\% (рис. 1).

Введение растворов фульвокислот в корнеобитаемую среду (питательный раствор) также привело к увеличению биомассы растений во всех исследуемых вариантах, с наиболее выраженным эффектом при концентрации 90,0 мг/л. Достоверное или в виде тенденции увеличение числа листьев и их площади в опытных вариантах обусловлено, вероятно, усилением процессов вторичного метаболизма, сопровождающихся ростом концентрации хлорофиллов и каротиноидов (на 8-118 \%), стимулирующих ассимиляционную работу листьев. При этом наблюдалось усиление эффективности фотосинтеза: рост ИЛП и ФП на 13-45 \% с максимальными показателями при выращивании растений на питательных растворах с введением фульвокислот в концентрациях 0,3 и 90,0 мг/л и ЧПФ на 6-20 \% с максимумом в концентрациях 30,0 и 150,0 мг/л (таблица 4).

Накопление витамина С и минеральных элементов в опытных вариантах не отличалось от аналогичных показателей в контрольном варианте или было достоверно ниже. Содержание углеводов достоверно выше контрольного отмечалось только в варианте с концентрацией фульвокислот 150,0 мг/л. В остальных вариантах данный показатель был на уровне контрольного или имел тенденцию к увеличению (таблица 5, рис. 1). По всей видимости, при введении растворов фульвокислот в корнеобитаемую среду накопление органических и минеральных веществ в листьях не служило решающим фактором в стимуляции процессов фотосинтеза.

Следует отметить увеличение (достоверное или в виде тенденции) содержания нитратов в листьях салата, наиболее выраженное при некорневой обработке растений растворами фульвокислот в концентрациях 0,3 и 3,0 мг/л; при поступлении фульвокислот в составе растворов из корнеобитаемой среды в концентрациях 0,3 и 150,0 мг/л. Отмеченное явление согласуется с литературными данными, согласно которым причиной этому может служить выявленная под влиянием фульвокислот стимуляция $\mathrm{H}^{+}$-АТФаз плазматической мембраны клеток корней, преобразующих свободную энергию, выделяемую при гидролизе АТФ, в трансмембранный электрохимический потенциал, используемый для импорта нитрата и других питательных веществ в корни и надземную часть. Помимо усвоения питательных веществ, АТФазы плазматической мембраны с помощью протонной накачки также способствуют разрыхлению клеточной стенки, укрупнению клеток и росту органов [26], [27].

Таким образом, стимуляция роста растений салата в результате некорневой обработки растворами фульвокислот преимущественно обусловлена усилением процессов обмена и поступлением необходимых растениям органических и минеральных элементов питания в надземную часть. Усиление углеводного питания и увеличение содержания магния и железа способствовало повышению эффективности фотосинтеза за счет активизации процессов первичного метаболизма, связанного с образованием и расщеплением сахаров, а также каталитическими свойствами ионов железа. Очевидно, что железо как кофактор множества ферментов задействовано в большом количестве метаболических процессов, происходящих в растениях.

При введении растворов фульвокислот в корнеобитаемую среду (питательный раствор) накопление биомассы и усиление эффективности фотосинтетических процессов происходит за счет интенсификации корневого питания и синтеза вторичных метаболитов - фотосинтетических пигментов -каротиноидов и особенно хлорофиллов, активно участвующих в окислительно-восстановительных и фотосинтетических процессах.

Обсуждение и выводы (Discussion and Conclusion)

1. Методом химического осаждения с последующей фильтрацией получены растворы фульвокислот из сапропелей и изучено в серии лабораторных и вегетационных экспериментов в регулируемых условиях интенсивной светокультуры их влияние на растения кресс-салата и листового салата при следующих способах обработки: замачивание семян, некорневое опрыскивание вегетирующих растений, введение в корнеобитаемую среду - питательный раствор при гидропонном выращивании растений методом NFT.

2. Установлено, что растворы фульвокислоты в концентрациях 0,3-150,0 мг/л после обработки ими семян кресс-салата оказывали наиболее выраженное стимулирующие влияние на биометрические показатели ростка и корня в концентрации 30,0 мг/л и не влияли на энергию прорастания и всхожесть семян.

3. В период вегетативного роста при некорневой обработке растворами фульвокислот наибольший положительный эффект проявился при концентрациях 3,0 и 150,0 мг/л. Стимуляция роста растений салата под действием тестируемых веществ преимущественно обусловлена усилением процессов обмена и поступлением необходимых растениям элементов питания в надземную часть и интенсификацией ассимиляционной активности листьев.

4. Введение растворов фульвокислот в корнеобитаемую среду (питательный раствор) способствовало усилению корневого питания и активизации синтеза фотосинтетических пигментов - хлорофиллов и каротиноидов, стимулирующих процессы фотосинтеза. Максимальный положительный эффект установлен при концентрации фульвокислот 90,0 мг/л.

5. Полученные данные свидетельствуют о перспективности дальнейшего изучения механизмов влияния фульвокислот на растения с целью создания эффективных биопрепаратов и технологии их применения в растениеводстве открытого и защищенного грунта, направленной на экологически дружественное повышение продуктивности сельскохозяйственных культур и эффективности продукционного процесса. 
Библиографический список

1. Taha A. A., Omar M. M., Ghazy M. A. Effect of humic and fulvic acids on growth and yield of Lettuce Plant // Journal of Soil Science and Plant Physiologyю. 2016. Vol. 7. No. 8. Pp. 517-522.

2. Кононихин А. С., Жеребкер А. Я., Казачков М. А., Григорьев А. С., Костюкевич Ю. И., Пеков С. И., Бочаров К. В., Попов И. А., Перминова И. В., Николаев Е. Н. Исследование молекулярного состава гуминовых веществ угля и торфа при помощи масс спектрометрии высокого разрешения в условиях оптимального электрораспыления // Известия РАН. Энергетика. 2017. № 1. С. 107-114.

3. Панкратов Д. А., Анучина М. М., Константинов А. И., Перминова И. В. Анализ динамики взаимодействия гуминовых веществ угля с металлическим железом // Журнал физической химии. 2019. Т. 93. № 7. С. 992-1001. 4. Кошелев А. В., Деревягина И. Д., Головков В. Ф., Каабак Л. В., Епифанова О. А., Мамонтов С. П., Елеев Ю. А., Глухан Е. Н. Химический состав гуминовых препаратов, полученных из торфа // Химия и технология органических веществ. 2019. № 1 (9). С. 25-37.

5. Yang R., Li Z., Huang M., Luo N., Wen J., Zeng G. Characteristics of fulvic acid during coprecipitation and adsorption to iron oxides-copper aqueous system // Journal of Molecular Liquids. 2019. Vol. 274. Pp. 664-672.

6. Zanin L., Tomasi N., Cesco S., Varanini Z., Pinton R. Humic Substances Contribute to Plant Iron Nutrition Acting as Chelators and Biostimulants // Frontiers in Plant Science. 2019. Vol. 10. Article number 675.

7. Pamela C., Louise N., Joseph W. K. Agricultural uses of plant biostimulants // Plant Soil. 2014. Vol. 383. Pp. 3-41.

8. Lotfi R., Kalaji H. M., Valizadeh G. R., Behrozyar E. K., Hemati A., Gharavi-Kochebagh P., Ghassemi A. Effects of humic acid on photosynthetic efficiency of rapeseed plants growing under different watering conditions [Электронный ресурс] // Photosynthetica. 2018. Vol. 56. Pp. 962-970. URL: https://link.springer.com/content/ pdf/10.1007/s11099-017-0745-9.pdf (дата обращения: 19.02.2021).

9. Никитин С. Н. Фотосинтетическая деятельность растений в посевах и динамика ростовых процессов при применении биологических препаратов // Успехи современного естествознания. 2017. № 1. С. 33-38.

10. Anjum S. A., Wang L., Farooq M., Xue L., Ali S. Fulvic acid application improves the maize performance under wellwatered and drought conditions // Journal of Agronomy and Crop Science. 2011. Vol. 197. Pp. 409-417.

11. Braziene Z., Paltanavicius V., Avizienyte D. The influence of fulvic acid on spring cereals and sugar beets seed germination and plant productivity // Environmental Research. 2021. Vol. 195. Article number 110824.

12. Wang Y., Yang R., Zheng J., Shen Z., Xu X. Exogenous foliar application of fulvic acid alleviate cadmium toxicity in lettuce (Lactuca sativa L.) // Ecotoxicology and Environmental Safety. 2019. Vol. 167. Pp. 10-19.

13. Silva R. R., Santos A. C. M., Carneiro J. S. S., Marques L. C., Rodrigues L. U., Faria A. J. G., Freitas G. A., Nascimento V. L. Biostimulants based on humic acids, amino acids and vitamins increase growth and quality of Lettuce seedlings // Journal of Agricultural Science. 2019. Vol. 11. No. 6. Pp. 235-246.

14. Suh H. Y., Yoo K. S., Sang G. S. Effect of foliar application of fulvic acid on plant growth and fruit quality of tomato (Lycopersicon esculentum L.) // Horticulture, Environment, and Biotechnology. 2014. Vol. 55. No. 6. Pp. 455-461.

15. Shahid M., Dumat C., Silvestre J., Pinelli E. Effect of fulvic acids on lead-induced oxidative stress to metal sensitive Vicia faba L. plant // Biology and Fertility of Soils. 2012. Vol. 48. Pp. 689-697.

16. Ali B., Wang B., Ali S., et al. 5-Aminolevulinic acid ameliorates the growth, photosynthetic gas exchange capacity, and ultrastructural changes under Cadmium stress in Brassica napus L. // Journal of Plant Growth Regulation. 2013. Vol. 32. No. 3. Pp. 604-614.

17. Tang W. W., Zeng G. M., Gong J. L., et al. Impact of humic/fulvic acid on the removal of heavy metals from aqueous solutions using nanomaterials: a review // Science of the Total Environment. 2014. Vol. 468. Pp. 1014-1027.

18. Митюков А. С., Румянцев В. А., Крюков Л. Н., Ярошевич Г. С. Сапропель и перспективы его использования в аграрном секторе экономики // Общество. Среда. Развитие. 2016. № 2. С. 110-114.

19. Орлов Д. С., Гришина Л. А. Практикум по химии гумуса. Москва, 1981. 272 с.

20. Panova G. G., Udalova O. R., Kanash E. V., Galushko A. S., Kochetov A. A., Priyatkin N. S., Arkhipov M. V., Chernousov I. N. Fundamentals of physical modeling of "ideal" agroecosystems // Technical Physics. 2020. Vol. 65. No. 10. Pp. 1563-1569.

21. ISTA, International Rules for Seed Testing. 2016. DOI: 10.15258/istarules.

22. Удалова О. Р., Пищик В. Н., Мирская Г. В., Вертебный В. Е., Воробьев Н. И., Хомяков Ю. В. Влияние биологически активных препаратов на продуктивность и качество плодов перца сладкого в условиях интенсивной светокультуры // Овощи России. 2018. № 3 (41). С. 81-85.

23. Удалова О. Р., Аникина Л. М., Хомяков Ю. В., Вертебный В. Г., Дубовицкая В. И., Панова Г. Г. Влияние тонкослойных аналогов почвы на продукционный процесс растений салата в интенсивной светокультуре // Овощи России. 2021. № 1. С. 33-38.

24. Руководство по методам анализа качества и безопасности пищевых продуктов. Москва, 1998. 342 с.

25. Пищик В. Н., Бойцова Л. В., Воробьев Н. И. Влияние гуминовых веществ на растения и ризосферные микроорганизмы в растительно-микробных системах // Агрохимия. 2019. № 3. С. 85-95.

26. Jindo K., Martim S. A., Navarro E. C., Aguiar N. O., Canellas L. P. Root growth promotion by humic acids from composted and non-composted urban organic wastes // Plant and Soil. 2012. Vol. 353. Pp. 209-220.

27. Jardin P. Plant biostimulants: Definition, concept, main categories and Regulation // Scientia Horticulturae. 2015. Vol. 196. Pp. 3-14. 
Об авторах:

Ольга Рудольфовна Удалова ${ }^{1}$, кандидат сельскохозяйственных наук, ведущий научный сотрудник, ORCID 0000-0003-3521-0254, AuthorID 124709; +7911940-79-80,udal59@inbox.ru

Галина Владимировна Мирская ${ }^{1}$, кандидат биологических наук, ведущий научный сотрудник,

ORCID 0000-0001-6207-736x, AuthorID 601902; galinanm@gmail.com

Павел Юрьевич Конончук ${ }^{1}$, ведущий научный сотрудник, ORCID 0000-0003-0449-5189, AuthorID 660151; 79117717774@yandex.ru

Гаяне Геннадьевна Панова ${ }^{1}$, кандидат биологических наук, ведущий научный сотрудник, ORCID 0000-0002-1132-9915, AuthorID 195449; gaiane@inbox.ru

${ }^{1}$ Агрофизический научно-исследовательский институт, Санкт-Петербург, Россия

\title{
About the influence of solutions of fulvic acids from sapropel on lettuce plants in various types of its processing
}

\author{
O. R. Udalova ${ }^{1 \bowtie}$, G. V. Mirskaya ${ }^{1}$, P. Yu. Kononchuk ${ }^{1}$, G. G. Panova ${ }^{1}$ \\ ${ }^{1}$ Agrophysical Research Institute, Saint Petersburg, Russia \\ E-mail:udal59@inbox.ru
}

Abstract. The purpose of our research was to assess the influence of treatment with fulvic acid (FA) solutions (ob-
tained from sapropel) on the physiological state, production process, and quality of salad crops under intensive con-
trolled conditions. Research method. Treatment of plants with solutions of FA in various concentrations was carried
out under controlled conditions using three different methods: soaking cress seeds $(0.03-300 \mathrm{mg} /$ ) $)$; non-root treatment
of vegetative plants $(90-150 \mathrm{mg} / 1$ ), when growing lettuce by a low - volume method with drip fertigation with Knop
nutrient solution; adding a nutrient solution to the root medium $(0.03-150 \mathrm{mg} / \mathrm{l}$ ), when growing lettuce under nutrient
film technique. Results. The most pronounced stimulating effect on plant growth was obtained after seeds treatment
with FA solutions in concentrations of $0.3-150.0 \mathrm{mg} / \mathrm{l}$, during non-root treatment of lettuce in concentrations of 0.3
and $150.0 \mathrm{mg} / \mathrm{l}$, and when FA was introduced into the root medium at a concentration of $90.0 \mathrm{mg} / \mathrm{l}$. It was suggested
the lettuce growth under the action of FA was conditioned by enhancing plants metabolism and increased entry of
nutrients to the aboveground organs of plants (during non - root processing)- and by nutrient uptake increasingas
well as activation of the synthesis of photosynthetic pigments-chlorophylls and carotenoids (when a nutrient solution
was add to the root medium. Scientific innovation. Under controlled conditions, a comprehensive assessment of
the effect of FA solutions obtained from sapropel on the physiological state, production process, and quality of salad
crops was carried out. The concentrations of fulvic acid solutions that had the most pronounced stimulating effect on
the growth and development of lettuce plants in various types of treatment were determined. The specificity of the
responses of lettuce plants to various types of treatment with FA solutions was revealed. Keywords: fulvic acid solutions, nutrient film technique, watercress, lettuce, seeds, soaking, non-root treatment, introduction to the root environment, growth, productivity, photosynthesis.

For citation: Udalova O. R., Mirskaya G. V., Kononchuk P. Yu., Panova G. G. O vliyanii rastvorov ful'vokislot iz sapropelya na rasteniya salata pri razlichnykh vidakh ego obrabotki [About the influence of solutions of fulvic acids from sapropel on lettuce plants in various types of its processing] // Agrarian Bulletin of the Urals. 2021. No. 06 (209). Pp. 22-33.. DOI: ... (In Russian.)

Date of paper submission: 09.03.2021, date of review: 28.04.2021, date of acceptance: 14.05.2021.

\section{References}

1. Taha A. A., Omar M. M., Ghazy M. A. Effect of humic and fulvic acids on growth and yield of Lettuce Plant // Journal of Soil Science and Plant Physiologyю. 2016. Vol. 7. No. 8. Pp. 517-522.

2. Kononikhin A. S., Zherebker A. Ya., Kazachkov M. A., Grigoryev A. S., Kostyukevich Yu. I., Pekov S. I., Bocharov K. V., Popov I. A., Perminova I. V., Nikolaev E. N. Issledovanie molekulyarnogo sostava guminovykh veshchestv uglya i torfa pri pomoshchi mass spektrometrii vysokogo razresheniya v usloviyakh optimal'nogo elektroraspyleniya [The study of the molecular composition of humic substances of coal and peat using high resolution mass spectrometry under optimal electrospray] // Izvestiya RAN. Enerketika. 2017. No. 1. Pp. 107-114. (In Russian.)

3. Pankratov D. A., Anuchina M. M., Konstantinov A. I., Perminova I. V. Analiz dinamiki vzaimodeystviya guminovykh veshchestv uglya s metallicheskim zhelezom [Analysis of the dynamics of the interaction of humic substances of coal with metallic iron] // Journal of Physical Chemistry. 2019. Vol. 93. No. 7. Pp. 992-1001. (In Russian.) 4. Koshelev A. V., Derevyagina I. D., Golovkov V. F., Kaabak L. V., Epifanova O. A., Mamontov S. P., Eleev Yu. A., Glukhan E. N. Khimicheskiy sostav guminovykh preparatov, poluchennykh iz torfa [Chemical composition of huminous compounds received from peat] // Chemistry and Technology of Organic Substances. 2019. No. 1 (9). Pp. 25-37. (In Russian.)

5. Yang R., Li Z., Huang M., Luo N., Wen J., Zeng G. Characteristics of fulvic acid during coprecipitation and ad32 Sorption to iron oxides-copper aqueous system // Journal of Molecular Liquids. 2019. Vol. 274. Pp. 664-672. 


\section{Agrarian Bulletin of the Urals No. 06 (209), 2021}

6. Zanin L., Tomasi N., Cesco S., Varanini Z., Pinton R. Humic Substances Contribute to Plant Iron Nutrition Acting as Chelators and Biostimulants // Frontiers in Plant Science. 2019. Vol. 10. Article number 675.

7. Pamela C., Louise N., Joseph W. K. Agricultural uses of plant biostimulants // Plant Soil. 2014. Vol. 383. Pp. 3-41.

8. Lotfi R., Kalaji H. M., Valizadeh G. R., Behrozyar E. K., Hemati A., Gharavi-Kochebagh P., Ghassemi A. Effects of humic acid on photosynthetic efficiency of rapeseed plants growing under different watering conditions [e-resource] // Photosynthetica. 2018. Vol. 56. Pp. 962-970. URL: https://link.springer.com/content/pdf/10.1007/s11099017-0745-9.pdf (date of reference: 19.02.2021).

9. Nikitin S. N. Fotosinteticheskaya deyatel'nost' rasteniy v posevakh i dinamika rostovykh protsessov pri primenenii biologicheskikh preparatov [Photosynthetic activity of plants in crops and dynamics of growth processes in the application of biological preparations] // Advances in current natural sciences. 2017. No. 1. Pp. 33-38. (In Russian.)

10. Anjum S. A., Wang L., Farooq M., Xue L., Ali S. Fulvic acid application improves the maize performance under wellwatered and drought conditions // Journal of Agronomy and Crop Science. 2011. Vol. 197. Pp. 409-417.

11. Braziene Z., Paltanavicius V., Avizienytė D. The influence of fulvic acid on spring cereals and sugar beets seed germination and plant productivity // Environmental Research. 2021. Vol. 195. Article number 110824.

12. Wang Y., Yang R., Zheng J., Shen Z., Xu X. Exogenous foliar application of fulvic acid alleviate cadmium toxicity in lettuce (Lactuca sativa L.) // Ecotoxicology and Environmental Safety. 2019. Vol. 167. Pp. 10-19.

13. Silva R. R., Santos A. C. M., Carneiro J. S. S., Marques L. C., Rodrigues L. U., Faria A. J. G., Freitas G. A., Nascimento V. L. Biostimulants based on humic acids, amino acids and vitamins increase growth and quality of Lettuce seedlings // Journal of Agricultural Science. 2019. Vol. 11. No. 6. Pp. 235-246.

14. Suh H. Y., Yoo K. S., Sang G. S. Effect of foliar application of fulvic acid on plant growth and fruit quality of tomato (Lycopersicon esculentum L.) // Horticulture, Environment, and Biotechnology. 2014. Vol. 55. No. 6. Pp. 455-461.

15. Shahid M., Dumat C., Silvestre J., Pinelli E. Effect of fulvic acids on lead-induced oxidative stress to metal sensitive Vicia faba L. plant // Biology and Fertility of Soils. 2012. Vol. 48. Pp. 689-697.

16. Ali B., Wang B., Ali S., et al. 5-Aminolevulinic acid ameliorates the growth, photosynthetic gas exchange capacity, and ultrastructural changes under Cadmium stress in Brassica napus L. // Journal of Plant Growth Regulation. 2013. Vol. 32. No. 3. Pp. 604-614.

17. Tang W. W., Zeng G. M., Gong J. L., et al. Impact of humic/fulvic acid on the removal of heavy metals from aqueous solutions using nanomaterials: a review // Science of the Total Environment. 2014. Vol. 468. Pp. 1014-1027.

18. Mityukov A. S., Rumyantsev V. A., Kryukov L. N., Yaroshevich G. S. Sapropel' i perspektivy ego ispol'zovaniya $\mathrm{v}$ agrarnom sektore ekonomiki [Sapropel and the prospects for its use in the agricultural sector of the economy] // Society. Enviroment. Development. 2016. No. 2. Pp. 110-114. (In Russian.)

19. Orlov D. S. Grishina L. A. Praktikum po khimii gumusa [Workshop on the chemistry of humus]. Moscow: Izd-vo MGU, 1981. 272 p. (In Russian.)

20. Panova G. G., Udalova O. R., Kanash E. V., Galushko A. S., Kochetov A. A., Priyatkin N. S., Arkhipov M. V., Chernousov I. N. Fundamentals of physical modeling of "ideal” agroecosystems // Technical Physics. 2020. Vol. 65. No. 10. Pp. $1563-1569$.

21. ISTA, International Rules for Seed Testing. 2016. DOI: 10.15258/istarules.

22. Udalova O. R., Pishchik V. N., Mirskaya G. V., Vertebnyy V. E., Vorobyev N. I., Khomyakov Yu. V. Vliyanie biologicheski aktivnykh preparatov na produktivnost' i kachestvo plodov pertsa sladkogo v usloviyakh intensivnoy svetokul'tury [Effect of biologically active preparations on productivity and quality of sweet pepper fruits in controlled conditions] // Vegetable crops of Russia. 2018. No. 3. Pp. 81-85. (In Russian.)

23. Udalova O. R., Anikina L. M., Khomyakov Yu. V., Vertebnyy V. E., Dubovitskaya V. I., Panova G. G. Vliyanie tonkosloynykh analogov pochvy na produktsionnyy protsess rasteniy salata $\mathrm{v}$ intensivnoy svetokul'ture [Influence of thin-layer soil analogues on the production process of lettuce plants in intensive artificial-light culture]// Vegetable crops of Russia. 2021. No. 1. Pp. 33-38. (In Russian.)

24. Rukovodstvo po metodam analiza kachestva i bezopasnosti pishchevykh produktov [Guidelines for food quality and safety analysis methods]. Moscow, 1998. 342 p. (In Russian.)

25. Pishchik V. N., Boytsova L. V., Vorob'ev N. I. Vliyanie guminovykh veshchestv na rasteniya i rizosfernye mikroorganizmy v rastitel'no-mikrobnykh sistemakh [Effect of humic substances on plants and rhizosphere microorganisms in plant-microbial systems] // Agrochemistry. 2019. No. 3. Pp. 85-95. (In Russian.)

26. Jindo K., Martim S. A., Navarro E. C., Aguiar N. O., Canellas L. P. Root growth promotion by humic acids from composted and non-composted urban organic wastes // Plant and Soil. 2012. Vol. 353. Pp. 209-220.

27. Jardin P. Plant biostimulants: Definition, concept, main categories and Regulation // Scientia Horticulturae. 2015. Vol. 196. Pp. 3-14.

\section{Authors'information:}

Olga R. Udalova ${ }^{1}$, candidate of agricultural sciences, leading researcher, ORCID 0000-0003-3521-0254, AuthorID 124709; +7911940-79-80,udal59@inbox.ru

Galina V. Mirskaya ${ }^{1}$, candidate of biological sciences, leading researcher, ORCID 0000-0001-6207-736x, AuthorID 601902; galinanm@gmail.com

Pavel Yu. Kononchuk ${ }^{1}$, leading researcher, ORCID 0000-0003-0449-5189, AuthorID 660151;

79117717774@yandex.ru

Gayane G. Panova ${ }^{1}$, candidate of biological sciences, leading researcher, ORCID 0000-0002-1132-9915, AuthorID 195449; gaiane@inbox.ru

${ }^{1}$ Agrophysical Research Institute, Saint Petersburg, Russia 